\title{
Mental health and employment: much work still to be done
}

Samuel B. Harvey, Max Henderson, Paul Lelliott and Matthew Hotopf

\section{Summary}

Mental illness is now the leading cause of both sickness absence and incapacity benefits in most high-income

countries. The rising economic and social costs make health and work an increasing priority for policy makers. We discuss the findings from Dame Carol Black's recent review of the health of Britain's working-age population and examine how her recommendations may impact and challenge mental health services.

\section{Declaration of interest}

P.L. is Chairman of First Step Trust, a national charity that provides work opportunities for people with mental health problems, and Director of the Royal College of Psychiatrists' Research and Training Unit, which was commissioned to write a report on mental health and work for the National Director for Health and Work. S.H., M. Henderson and P.L. were co-authors of this report. Funding detailed in Acknowledgements.
Samuel Harvey (pictured), Max Henderson and Matthew Hotopf are clinica academics at the Institute of Psychiatry, King's College London. Paul Lelliott is a consultant psychiatrist at Oxleas NHS Trust.

High levels of sickness absence and increasing numbers on incapacity benefits have made health and work a major priority for policy-makers in most high-income countries. Professor Dame Carol Black, the UK National Director for Health and Work, recently published her in-depth review of the health of Britain's working-age population. ${ }^{1}$ The conclusions and recommendations from her report are already having significant policy implications. The government's formal reply to this report has recently been published together with a Green Paper 'No one written off: reforming welfare to reward responsibility.' ${ }^{2}$ These documents make it clear that the UK National Health Service (NHS) will be asked to do much more to help people remain at work. Similar policy initiatives aimed at increasing work participation among individuals previously supported on disability benefits have been implemented in many other high-income countries. ${ }^{3}$ The international drive to decrease rates of illness-related worklessness will create particular challenges for mental health services whose patients are highly disadvantaged in the workplace. However, this process might also provide unique opportunities to change the way mental healthcare is delivered.

\section{Health of the working-age population}

Across the UK economy, about 175 million working days were lost owing to sickness absence in 2006, equivalent to 7 days for each worker. ${ }^{4}$ The proportion of the working-age population on incapacity benefits has increased from just over $2 \%$ in the 1970 s to around $7 \%$ today. ${ }^{1}$ As a result, the total annual cost of sickness-related absence and worklessness in Britain has risen to more than $\mathfrak{E} 100$ billion, greater than the entire NHS budget. ${ }^{1}$ Similar figures can be quoted for other high-income countries. In the USA, $10 \%$ of all social expenditure is on disability benefits, while in Norway the proportion is just over $20 \% .^{3}$ However, these figures do not capture the full health and social costs. The adverse economic and health effects of worklessness are felt not only by the individuals who are not working, but also by their children. ${ }^{5}$ The corollary of this is that there is good evidence that in most situations the benefits of work for an individual's mental and physical health outweigh any risks. ${ }^{6}$

\section{Mental health and work}

Mental disorders are now the leading cause of sickness absence in most high-income countries, accounting for around $40 \%$ of the total time covered by sick notes. ${ }^{7}$ Within Organization for Economic Cooperation and Development (OECD) countries (comprising much of Europe, the USA, Canada, Mexico, Australia, New Zealand, Japan and Korea) mental illness now accounts for $35 \%$ of all disability benefits. ${ }^{3}$ In recognition of the importance of mental illness, Professor Black commissioned a separate report on work and mental health from the Royal College of Psychiatrists' Research and Training Unit. ${ }^{8}$ This describes two separate groups; those with symptoms of common mental disorders, who account for the majority of the costs related to mental ill-health, and a smaller group with severe mental illness, of whom it is estimated only $10-20 \%$ are in paid employment. ${ }^{9}$

Although these two groups have somewhat different needs and experiences, they do share a number of employment-related problems such as stigma, discrimination and a benefits system which provides perverse incentives for them to remain out of the workforce. There is, however, a significant difference in the evidence base for occupational interventions in these two groups, with much more known about how to help those with severe mental illness. There have been a number of randomised controlled trials that have evaluated the effectiveness of supportive treatment, in particular individual placement and support. These show that this is an effective occupational intervention for people with severe mental illness who believe that they are ready for open employment. ${ }^{10,11}$ However, it tends to lead only to entry-level jobs and there remain questions about long-term outcomes. ${ }^{8}$ Supportive employment programmes differ from more traditional 'train and place' programmes by providing direct job placements, then providing support to both the client and the employer. ${ }^{12}$ Although their economic benefits are not yet proven, supported employment schemes have been found to be effective within first-episode services, where the economic returns to the labour market are likely to be greatest. ${ }^{13}$ The UK government has acknowledged this evidence base by recommending an individual placement and support approach in its recent Commissioning Guidance on vocational services for people with severe mental health problems. ${ }^{14}$ Common mental disorders have a greater public health impact. Arguably, much of the long-term sickness absence caused by such disorders is preventable, but evidence is lacking on schemes to prevent such outcomes and to help those with long-term sickness absence get back to work. 


\section{Key recommendations from the report}

Professor Black makes a number of bold recommendations. ${ }^{1}$ She concludes that a fundamental shift is needed in the perception of fitness for work; specifically, the commonly held idea that it is not appropriate for people to work unless they are $100 \%$ fit and healthy. She acknowledged that this can only be achieved by engaging with and educating the wider public, employers and employees and by better training of healthcare professionals on employment issues. Her report proposed a switch from the current paper-based sick-note system to an electronic 'fit note' which focuses on what people can do rather than what they cannot. The introduction of these changes would require a highly responsive service for people referred by their general practitioner in the early stages of sickness absence and much closer joint working between occupational health services and the NHS. The exact model of this proposed new 'fit for work' service is yet to be decided, making it difficult to know how this will interact with current primary and secondary health services.

Although much of her focus is on early intervention, Professor Black's report also highlighted the economic, social and moral arguments for not overlooking those already on long-term sick leave or incapacity benefits, many of whom suffer from mental illness. The UK government has already committed to a national roll-out of the 'Pathways to Work' programme which is intended to divert people from the path that leads to long-term sickness absence, and work is now beginning on a new national strategy for mental health and employment.

\section{Implications for mental health services}

The majority of people not working owing to mental health problems have common mental disorders such as depression and anxiety. Furthermore, many patients with physical symptoms and disorders (particularly back pain and other musculoskeletal symptoms) have undiagnosed mental disorders. The management of these conditions is usually undertaken within primary care services where rates of detection are low and treatment often sub-optimal. ${ }^{15}$ Because most secondary mental health services focus on severe mental illness, they have limited capacity to advise and support primary care workers to manage their more difficult cases. This increases the risk that people with more complicated forms of common mental disorder end up on long-tem sickness absence or incapacity benefits. The Improving Access to Psychological Therapies (IAPT) initiative may reduce some of this service gap in England. ${ }^{16}$ The UK government has now announced that they will begin placing employment advisors as part of the IAPT programme in a pilot project beginning in early 2009 . $^{2}$

Early evidence suggests that, for those people on the road to long-term sickness absence, schemes such as the 'Pathways to Work' programme are less effective in reducing the rates of incapacity benefits owing to mental illness compared with physical ill health. ${ }^{17}$ The reasons for this failure are not clear, although evaluation of employment schemes in the USA suggests the more successful employment support programmes tend to be those closely integrated with clinical care. ${ }^{18}$ On 27 October 2008 Britain's incapacity benefit scheme was replaced by the employment support allowance (ESA). Under ESA, claimants who are not easy to place back into employment are assigned to the 'support group' who will receive less active help in getting back to work. It is likely that the support group will contain a disproportionately high number of people with mental illness. These concerns are further heightened by recent comments from David Freud, an advisor to the government on welfare reform.
In an interview with the Daily Telegraph newspaper he described a system where the market would decide who should receive benefits. He stated:

'The private sector will have to start making assessments about who they can get back into work at what cost. If somebody is really clinically depressed, for example, [the company] might say, "I'm not going to get this guy to hold down a job for 3 years because he's not up to it, so I'm not going to expend my efforts on him at the moment." '19

Such comments hint at a system that will further stigmatise those with mental illness and ignores evidence demonstrating that most people with depression respond to treatment with improved occupational functioning. ${ }^{20}$

Despite the rhetoric of social inclusion and recovery, secondary mental health services tend to focus on crisis care and risk management for those with more severe mental illness. This is due to a combination of financial constraints and public and political preoccupation with risk. The emphasis on risk management has been at the expense of other rehabilitation goals, including employment. Work rehabilitation programmes are poorly developed and unevenly distributed, and many specialised rehabilitation professionals, such as occupational therapists, are now working as generic mental healthcare workers. ${ }^{21}$ Mental health teams were criticised in a recent Healthcare Commission review for their 'low expectations' of what people with mental illness should be able to achieve in terms of employment. ${ }^{22}$

The Black review and the expected new policy initiatives that will follow should cause us to reconsider how mental health services address the employment needs of patients. Ironically, just as the move away from rehabilitation appears to have been driven by external financial and policy pressures, it is political and economic concerns regarding the relationship between mental health and work that may now provide an opportunity for mental health services to extend their remit. Both service users and mental health workers must be involved in shaping the changes to service delivery that will be required to meet the recommendations in Professor Black's report. We must acknowledge the importance of work for people with mental illness and begin to fill the research gaps, especially with regard to common mental disorders. The Royal College of Psychiatrists has signed a consensus statement on health and work, ${ }^{23}$ which pledges a commitment to promote and develop ways of supporting individuals to achieve the socio-economic and health benefits of work. If this pledge is to be met, we must examine how employment and other rehabilitation issues are addressed within mental health services and actively campaign for the resources to improve them.

Samuel B. Harvey, MRCPsych, Max Henderson, MRCPsych, Institute of Psychiatry, King's College London; Paul Lelliott, MRCPsych, Royal College of Psychiatrists' Research and Training Unit; Matthew Hotopf, PhD, Institute of Psychiatry, King's College London, UK

Correspondence: Dr Samuel B. Harvey, Institute of Psychiatry, King's College London, Department of Psychological Medicine, Weston Education Centre 10 Cutcombe Road, London SE5 9RJ, UK. Email: s.harvey@iop.kcl.ac.uk

First received 20 May 2008, final revision 11 Aug 2008, accepted 27 Aug 2008

\section{Acknowledgements}

S.H. and M. Hotopf are funded by the NIHR Biomedical Research Centre for Mental Health, The South London and Maudsley NHS Foundation Trust, and the Institute of Psychiatry, King's College London. M. Henderson is supported by a UK Medical Research Council Training Fellowship in Health Services and Health of the Public Research.

\section{References}

1 Black C. Working for a Healthier Tomorrow. TSO (The Stationery Office), 2008.

2 Department for Work and Pensions \& Department of Health. Improving Health and Work: Changing Lives. The Government's Response to Dame 
Carol Black's Review of the Health of Britain's Working-Age Population. TSO (The Stationery Office), 2008.

3 Organisation for Economic Cooperation and Development. Transforming Disability into Ability: Policies to Promote Work and Income Security for Disabled People. OECD, 2003

4 Confederation of British Industry. Attending to Absence. CBI/AXA Absence and Labour Turnover Survey 2006. CBI, 2007.

5 Reinhardt Pedersen C, Madsen M. Parents' labour market participation as predictor of children's health and wellbeing: a comparative study in five Nordic countries. J Epidemiol Community Health 2002; 56: 861-7.

6 Waddel G, Burton A. Is Work Good for your Health and Well-Being? TSO (The Stationary Office), 2006.

7 Shiels C, Gabbay MB, Ford FM. Patient factors associated with duration of certified sickness absence and transition to long-term incapacity. $\mathrm{Br} J \mathrm{Gen}$ Pract 2004; 54: 86-91.

8 Lelliott P, Tulloch S, Boardman J, Harvey S, Henderson M, Knapp M. Mental Health and Work (http://www.workingforhealth.gov.uk/documents/mentalhealth-and-work.pdf). Health, Work, Wellbeing, 2008.

9 Kooyman I, Dean K, Harvey S, Walsh E. Outcomes of public concern in schizophrenia. Br J Psychiatry 2007; 191 (suppl 50): s29-36.

10 Burns T, Catty J, Becker T, Drake RE, Fioritti A, Knapp M, et al. The effectiveness of supported employment for people with severe mental illness: a randomised controlled trial. Lancet 2007; 370: 1146-52.

11 Crowther RE, Marshall M, Bond GR, Huxley P. Helping people with severe mental illness to obtain work: systematic review. BMJ 2001; 322: 204-8.

12 Bond GR. Supported employment: evidence for an evidence-based practice. Psychiatr Rehabil J 2004; 27: 345-59.

13 Rinaldi M, McNeil K, Firn M, Koletsi M, Perkins R, Singh SP. What are the benefits of evidence-based supported employment for patients with firstepisode psychosis? Psychiatr Bull 2004; 28: 281-4.
14 National Social Inclusion Programme, National Institute for Mental Health in England \& Care Services Improvement Partnership. Vocational Services for People with Severe Mental Health Problems: Commissioning Guidance. Department of Health \& Department of Work and Pensions, 2006.

15 Kessler D, Lloyd K, Lewis G, Gray DP. Cross sectional study of symptom attribution and recognition of depression and anxiety in primary care. $B M J$ 1999; 318: 436-9.

16 Department of Health. Improving Access to Psychological Therapies. Implementation Plans: National Guidelines for Regional Delivery. Department of Health, 2008

17 Blyth B. Incapacity Benefit Reforms - Pathways to Work Pilots Performance and Analysis. Department of Work and Pensions, 2006.

18 Bond GR, Becker DR, Drake RE, Rapp CA, Meisler N, Lehman AF, et al. Implementing supported employment as an evidence-based practice. Psychiatr Serv 2001; 52: 313-22.

19 Sylvester R, Thomson A. Welfare is a mess, says adviser David Freud. Daily Telegraph 2008; 2 February.

20 Simon GE, Barber C, Birnbaum HG, Frank RG, Greenberg PE, Rose RM, et al. Depression and work productivity: the comparative costs of treatment versus nontreatment. J Occup Environ Med 2001; 43: 2-9.

21 Filson $P$, Kendrick T. Survey of roles of community psychiatric nurses and occupational therapists. Psychiatr Bull 1997; 21: 70-3.

22 Healthcare Commission \& Commission for Social Care Inspection. No Voice, No Choice. A Joint Review of Adult Community Mental Health Services in England. Commission for Healthcare Audit and Inspection, 2007.

23 Working for Health. Health, work, wellbeing. Healthcare professionals' consensus statement. Working for Health, 2008 (http:// www.workingforhealth.gov.uk/documents/healthcare-professionalsconsensus-statement-4-march-2008.pdf) 